\title{
Characterisation of mechanical and thermal properties in flax fabric reinforced geopolymer composites
}

\author{
Hasan $\operatorname{ASSAEDI}^{a}$, Thamer ALOMAYRI ${ }^{a}$, Faiz U. A. SHAIKH ${ }^{b}$, It-Meng LOW ${ }^{a, c, *}$ \\ ${ }^{a}$ Department of Imaging \& Applied Physics, Curtin University, GPO Box U1987, Perth, WA 6845, Australia \\ ${ }^{b}$ Department of Civil Engineering, Curtin University, GPO Box U1987, Perth, WA 6845, Australia \\ ${ }^{c}$ Department of Engineering, Curtin College, Building 205, Curtin University Bentley Campus, Kent Street, Perth, \\ Western Australia 6102, Australia
}

Received: February 19, 2015; Revised: June 17, 2015; Accepted: June 18, 2015

(C) The Author(s) 2015. This article is published with open access at Springerlink.com

\begin{abstract}
This paper presents the mechanical and thermal properties of flax fabric reinforced fly ash based geopolymer composites. Geopolymer composites reinforced with 2.4, 3.0 and $4.1 \mathrm{wt} \%$ woven flax fabric in various layers were fabricated using a hand lay-up technique and tested for mechanical properties such as flexural strength, flexural modulus, compressive strength, hardness, and fracture toughness. All mechanical properties were improved by increasing the flax fibre contents, and showed superior mechanical properties over a pure geopolymer matrix. Fourier transform infrared spectroscopy (FTIR) and scanning electron microscopy (SEM) studies were carried out to evaluate the composition and fracture surfaces of geopolymer and geopolymer/flax composites. The thermal behaviour of composites was studied by thermogravimetric analysis (TGA) and the results showed significant degradation of flax fibres at $300{ }^{\circ} \mathrm{C}$.
\end{abstract}

Keywords: geopolymer composites; flax fibre; mechanical properties; thermal properties

\section{Introduction}

Ordinary Portland cements are used in many construction applications because of their good mechanical and durability properties. However, the greenhouse emissions caused by cement based materials have made it necessary to find an eco-friendly alternative. A new group of promising construction material is geopolymer, first introduced and named by Davidovits in 1989, exhibiting good mechanical performance, durability, and fire and acid resistance. It can be cured and hardened at room temperature with $80 \%-90 \%$ fewer $\mathrm{CO}_{2}$ emissions than Portland

\footnotetext{
* Corresponding author.

E-mail: j.low@curtin.edu.au
}

cement [1-5].

Despite their desirable characteristics, geopolymer matrices suffer from brittle failure under applied force and demonstrate low flexural strength ranging between 1.7 and $16.8 \mathrm{MPa}[6,7]$. Improving their flexural and tensile strengths will significantly increase the application of these materials in the construction and building industries; and this may be accomplished by dispersing inorganic or organic fibres throughout the matrices. Hitherto, the most common fibre reinforcements used in geopolymer composites are based on carbon, basalt, and glass fibres [8-12], but concerns over the environment and non-biodegradability have made renewed interest recently in replacing the synthetic fibres used in geopolymer or other brittle matrices with natural plant 
fibres. These include flax, hemp, jute, pineapple, straw, switch grass, kenaf, coir, and bamboo [13,14]. These plant fibres cost less, have low density, and display good mechanical properties when compared with industrial fibres [15]. For example, natural fibres have lower densities than synthetic fibres generally, with many almost $30 \%-50 \%$ less dense than their synthetic counterparts [16]. They are also renewable, recyclable, and biodegradable, and demonstrate excellent mechanical characteristics like flexibility, high specific strength, and high specific modulus [17,18]. For example, wood-derived cellulose can be used for toughening epoxy and other polymers [19-22], and bamboo fibres improve the flexural strength of concrete [23]; the same desirable effect has been observed in wood fibre reinforced concrete [24]. Cotton fabrics also enhance the strength and toughness of geopolymer [25], and wool and flax fibres have been successfully used to reinforce geopolymer composites, with improvements in mechanical and fracture properties [26,27]. However, no study so far has reported the mechanical properties of flax fabric (FF) reinforced fly ash based geopolymer composites despite their advantages of cheapness, ready availability, lack of toxicity, biodegradability, and good tensile strength. The present report describes the development and mechanical properties of new environmentally friendly geopolymer composites reinforced with the readily-available natural flax fibres of Australia, to produce materials with excellent flexural strength and graceful failure properties.

This study considers the viability of developing a green composite material that uses fly ash geopolymer as the matrix and FF as the reinforcement. Fourier transform infrared spectroscopy (FTIR), scanning electron microscopy (SEM), and thermogravimetric analysis (TGA) are used to investigate the morphology, microstructure, failure mechanisms, and thermal behaviour of geopolymer/flax composites. The effect of different FF contents of 2.4, 3.0, and $4.1 \mathrm{wt} \%$ on mechanical properties of the composites such as flexural strength, flexural modulus, compressive strength, hardness, and fracture toughness is also presented in this paper.

\section{Experimental procedures}

\section{1 Materials}

Flax fabric shown in Fig. 1, supplied by Pure Linen

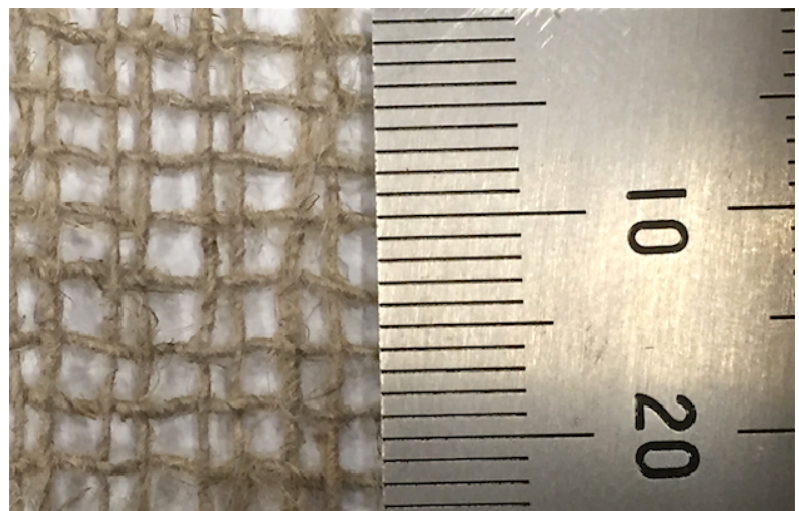

Fig. 1 Structure of the flax fabric.

Australia, was used as reinforcement in the fabrication of geopolymer composites. The structure and physical properties of the flax fabric are shown in Table 1. Low calcium fly ash (ASTM class F) collected from the Eraring power station in New South Wales, Australia, was used as the source material for the geopolymer matrix. The chemical composition of fly ash is shown in Table 2. The alkaline activator for geopolymerisation was a combination of sodium hydroxide and sodium silicate grade D solution. Sodium hydroxide flakes of $98 \%$ purity were used to prepare the solution. The chemical composition of sodium silicate used was $14.7 \% \mathrm{Na}_{2} \mathrm{O}, 29.4 \% \mathrm{SiO}_{2}$, and $55.9 \%$ water by mass.

To prepare the geopolymer composites, an alkaline solution to fly ash ratio of 0.75 was used, and the ratio of sodium silicate solution to sodium hydroxide solution was fixed at 2.5. The concentration of sodium hycloxide solution was $8 \mathrm{M}$, and was prepared and combined with the sodium silicate solution one day before mixing.

The alkaline solution was added to the fly ash in a Hobart mixer at low speed until the mix became homogeneous, then mixed for another $10 \mathrm{~min}$ on high speed with an additional $50 \mathrm{~mL}$ of water to improve the workability. This produced a geopolymer matrix of molar composition of $\mathrm{SiO}_{2} / \mathrm{Al}_{2} \mathrm{O}_{3}=4.16, \mathrm{Na}_{2} \mathrm{O} / \mathrm{SiO}_{2}=$ 0.37, and $\mathrm{H}_{2} \mathrm{O} / \mathrm{Na}_{2} \mathrm{O}=11.43$.

Table 1 Structure and physical properties of the flax fabric

\begin{tabular}{ll}
\hline Fabric thickness $(\mathrm{mm})$ & 0.6 \\
Fabric geometry & Woven (plain weave) \\
Yarn nature & Bundle \\
Bundle diameter (mm) & 0.6 (see Fig. 2(a)) \\
Filament size $(\mathrm{mm})$ & $0.01-0.02$ (see Fig. 2(b)) \\
Opening size $(\mathrm{mm})$ & $2-4$ \\
Fabric density $\left(\mathrm{g} / \mathrm{cm}^{3}\right)$ & 1.5 \\
Modulus of elasticity $(\mathrm{GPa})$ & 39.5 \\
Tensile strength (MPa) & 660 \\
\hline
\end{tabular}


Table 2 Chemical composition of fly ash

(Unit: $w t \%)$

\begin{tabular}{ccccccccccccc}
\hline $\mathrm{SiO}_{2}$ & $\mathrm{Al}_{2} \mathrm{O}_{3}$ & $\mathrm{CaO}$ & $\mathrm{Fe}_{2} \mathrm{O}_{3}$ & $\mathrm{~K}_{2} \mathrm{O}$ & $\mathrm{MgO}$ & $\mathrm{Na}_{2} \mathrm{O}$ & $\mathrm{P}_{2} \mathrm{O}_{5}$ & $\mathrm{SO}_{3}$ & $\mathrm{TiO}_{2}$ & $\mathrm{MnO}$ & $\mathrm{BaO}_{2}$ & $\mathrm{LOI}_{2}$ \\
\hline 63.13 & 24.88 & 2.58 & 3.07 & 2.01 & 0.61 & 0.71 & 0.17 & 0.18 & 0.96 & 0.05 & 0.07 & 1.45 \\
\hline
\end{tabular}
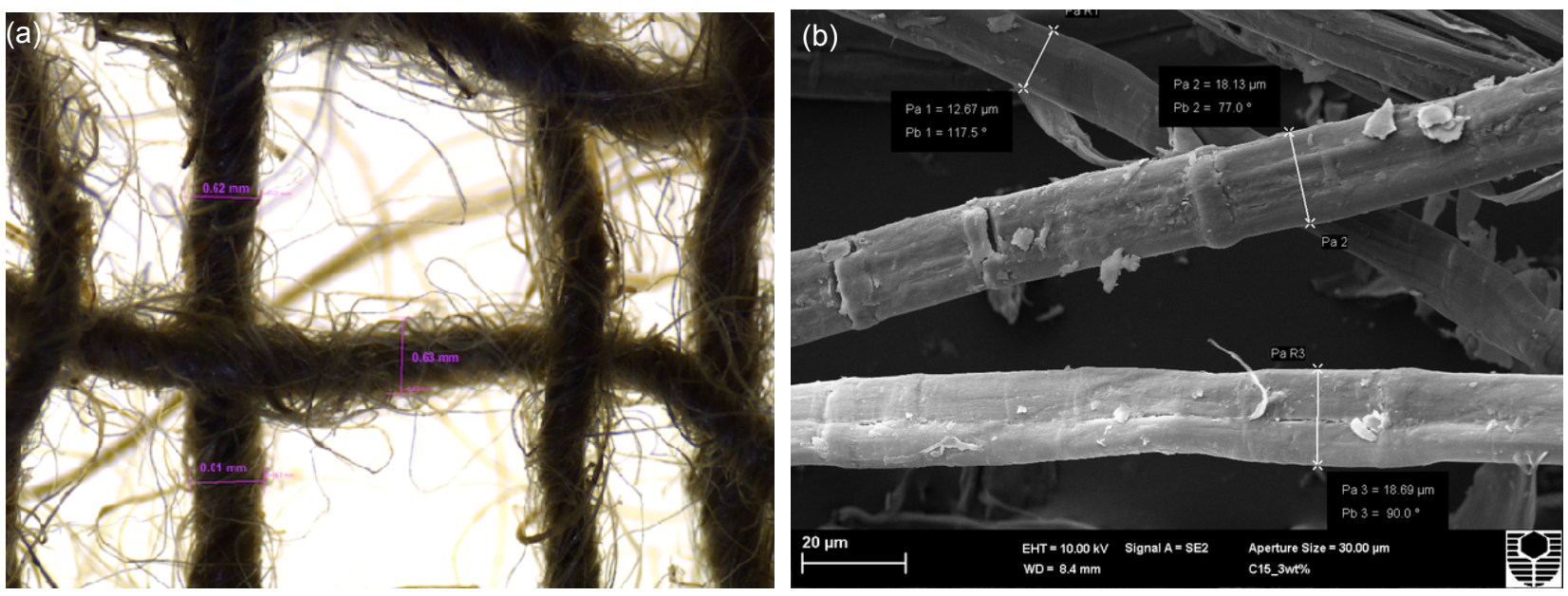

Fig. 2 Diameters of the (a) flax bundle and (b) flax fibres.

Three samples of geopolymer composites reinforced with $2.4,3.0$, and $4.1 \mathrm{wt} \% \mathrm{FF}$ were prepared by spreading a thin layer of geopolymer paste in a well greased wooden mould and carefully laying the first layer of FF on top. The fabric was fully saturated with paste by a roller, and the process repeated for the desired number of layers; each specimen contained a different number of layers of FF (see Table 3). For each specimen, the final layer was geopolymer paste. The wooden moulds were then placed on a vibration table for $2 \mathrm{~min}$, then covered with plastic film and cured at $80{ }^{\circ} \mathrm{C}$ for $24 \mathrm{~h}$ in an oven before demoulding. They were then dried under ambient conditions for 28 days. This procedure of preparing geopolymer composites is reported by Alomayri et al. [25].

\section{2 Mechanical properties}

A LLOYD material testing machine (50 kN capacity) with a displacement rate of $0.5 \mathrm{~mm} / \mathrm{min}$ was used to perform the mechanical tests. Rectangular bars of $60 \mathrm{~mm} \times 18 \mathrm{~mm} \times 15 \mathrm{~mm}$ with a span of $40 \mathrm{~mm}$ were cut from the fully cured samples for three-point bend tests to evaluate the mechanical properties. All samples

Table 3 Formulation of samples

\begin{tabular}{cccccc}
\hline Sample & $\begin{array}{c}\text { Fly } \\
\text { ash } \\
(\mathrm{g})\end{array}$ & $\begin{array}{c}\mathrm{NaOH} \\
\text { solution } \\
(\mathrm{g})\end{array}$ & $\begin{array}{c}\mathrm{Na}_{2} \mathrm{SiO}_{3} \\
\text { solution } \\
(\mathrm{g})\end{array}$ & $\begin{array}{c}\text { Fabric } \\
\text { layers }\end{array}$ & $\begin{array}{c}\mathrm{FF} \\
\text { content } \\
(\mathrm{wt} \%)\end{array}$ \\
\hline 1 & 1000 & 214.5 & 535.5 & 0 & 0 \\
2 & 1000 & 214.5 & 535.5 & 5 & 2.4 \\
3 & 1000 & 214.5 & 535.5 & 7 & 3.0 \\
4 & 1000 & 214.5 & 535.5 & 10 & 4.1 \\
\hline
\end{tabular}

were aligned horizontally to the applied load in all mechanical tests. Ten samples of each composite were used to evaluate the flexural strength and the flexural modulus according to the standard ASTM D790 [28]. The values were recorded and analysed with the machine software (NEXYGENPlus) and average values were calculated. The flexural strength $\left(\sigma_{\mathrm{F}}\right)$ was determined using the equation:

$$
\sigma_{\mathrm{F}}=\frac{3}{2} \frac{p_{\mathrm{m}} S}{W D^{2}}
$$

where $p_{\mathrm{m}}$ is the maximum load; $S$ is the span of the sample; $D$ is the specimen width; and $W$ is the specimen thickness.

Flexural modulus $\left(E_{\mathrm{F}}\right)$ values were computed using the initial slope of the load displacement curve ( $\Delta P / \Delta X)$ using the equation [29]:

$$
E_{\mathrm{F}}=\frac{S^{3}}{4 W D^{3}}\left(\frac{\Delta P}{\Delta X}\right)
$$

A crack with a length to width ratio $(a / W)$ of 0.4 was introduced into the specimen using a $0.4 \mathrm{~mm}$ diamond blade, to evaluate fracture toughness. The fracture toughness $\left(K_{\text {IC }}\right)$ was calculated using the equation [29]:

$$
K_{\mathrm{IC}}=\frac{p_{\mathrm{m}} S}{W D^{2 / 3}} f\left(\frac{a}{W}\right)
$$

where $a$ is the crack length, and $f(a / W)$ is the polynomial geometrical correction factor given by [29]:

$$
f\left(\frac{a}{W}\right)=3(a / W)^{1 / 2}[1.99-(a / W)(1-a / W) \times
$$




$$
\begin{aligned}
& \left.\left(2.15-3.93 a / W+2.7 a^{2} / W^{2}\right)\right] / \\
& {\left[2(1+2 a / W)(1-a / W)^{2 / 3}\right]}
\end{aligned}
$$

The compressive strength of the geopolymer composites was tested according to ASTM C109 [30], but instead of using the recommended $50 \mathrm{~mm}$ cube specimens, $20 \mathrm{~mm}$ cubes were used. The compressive strength $(C)$ of the sample was calculated using the following formula:

$$
C=P / A
$$

where $P$ is maximum load on the sample at failure and $A$ is the surface area of the specimen.

The hardness of geopolymer composites was measured on the Rockwell $\mathrm{H}$ scale using an Avery Rockwell hardness tester. Before measurement, five samples were polished with emery paper to achieve flat, smooth surfaces.

\section{3 Characterisation}

An FTIR spectrum was performed on a Perkin Elmer Spectrum 100 FTIR spectrometer in the range of $4000-500 \mathrm{~cm}^{-1}$ at room temperature. The spectrum was an average of 10 scans at a resolution of $2 \mathrm{~cm}^{-1}$, corrected for background.

The microstructures of geopolymer composites were examined using a Zeiss Neon focused ion beam scanning electron microscope (FIB-SEM). The specimens were mounted on aluminium stubs using carbon tape and then coated with a thin layer of platinum to prevent charging before the observation.

A thermogravimetric analyser (TGA) was used to examine the thermal behaviours of the composites. Solid samples of $25 \mathrm{mg}$ were placed in an alumina crucible and tests were carried out in an argon atmosphere with a heating rate of $10{ }^{\circ} \mathrm{C} / \mathrm{min}$ from 25 to $800{ }^{\circ} \mathrm{C}$.

\section{Results and discussion}

\section{1 FTIR observation}

FTIR spectra of both pure geopolymer and flax/geopolymer composite are shown in Fig. 3. The strong peak at $\sim 1000 \mathrm{~cm}^{-1}$ is associated with $\mathrm{Al}-\mathrm{O}$ and $\mathrm{Si}-\mathrm{O}$ asymmetric stretching vibrations and is the fingerprint of the geopolymerisation [31]. The FTIR spectra show a broad peak in the region at $3466 \mathrm{~cm}^{-1}$ corresponding to the hydroxyl $(\mathrm{OH})$ stretching vibration of free and hydrogen bonded-OH groups [32,33], and

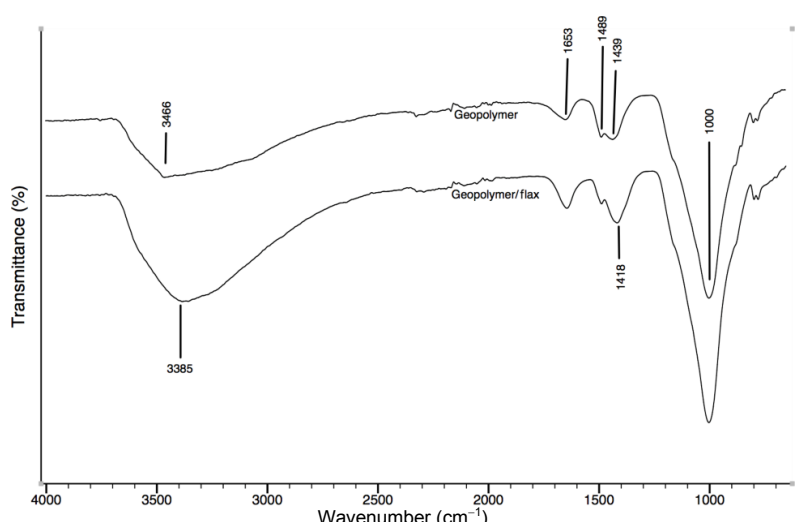

Fig. 3 FTIR spectra of pure geopolymer and flax/geopolymer composite.

the absorbance peak around $1653 \mathrm{~cm}^{-1}$ is attributed to the bending vibration of absorbed water $[34,35]$. The presence of bands in the regions $1440-1490 \mathrm{~cm}^{-1}$ is an indicator of the atmospheric carbonation on the surface of the matrix where it reacts with carbon dioxide [34]. The presence of flax fibres in the composites can be recognised by the peak at $1418 \mathrm{~cm}^{-1}$, which is attributed to the $\mathrm{CH}_{3}$ bending vibration of cellulose [32]. The intensity of the bands at 3385 and $1653 \mathrm{~cm}^{-1}$ increases in response to the existence of absorbed water in the cellulose fibres.

\section{2 Flexural strength and modulus}

Generally, flexural tests are used to characterise the mechanical properties of layered composites as they provide a simple means of determining the bending response. This provides useful information on the performance of layered fabric based composites [36]. The effect of FF contents on the flexural stress-strain curves of the geopolymer composites is presented in Fig. 4.

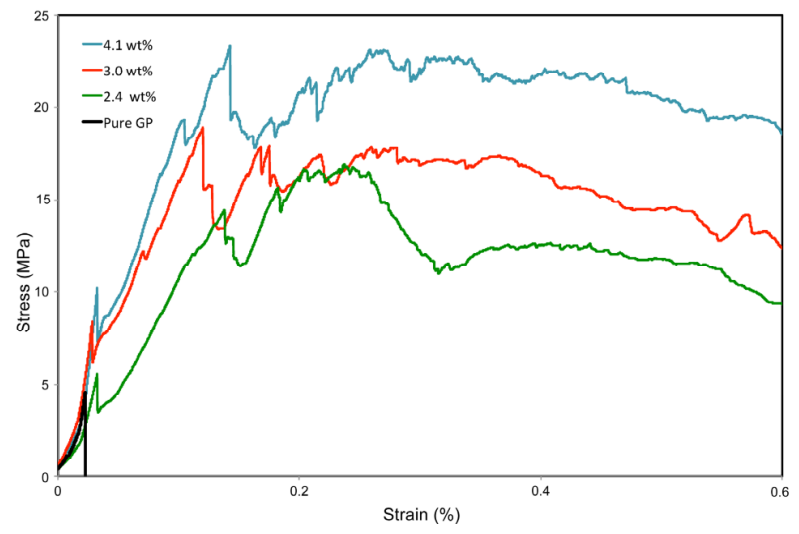

Fig. 4 Typical stress-strain curves of pure geopolymer and geopolymer composites with various FF contents. 
It can be seen that, the composite containing $4.1 \mathrm{wt} \%$ FF shows the highest flexural strength among all composites. The flexural strength of the composites improves from $4.5 \mathrm{MPa}$ in the pure geopolymer to about $23 \mathrm{MPa}$ with $4.1 \mathrm{wt} \% \mathrm{FF}$. This result is comparable with that of short flax fibre reinforced geopolymer composites reported by Alzeer and MacKenzie [27]. Both studies show that increasing the content of flax fibres leads to a significant improvement in the flexural strength of the composite. This can be explained by the fact that the number of reinforcement layers controls the flexural strength. The lower weight of flax fabrics allows multiple layers of fabric in the composite to resist the shear failure and contribute in sustaining the applied load to the composites. This permits greater stress transfer between the matrix and the flax fibres, resulting in improved flexural strength [37].

The flexural modulus of geopolymer composites, shown in Fig. 5, also indicates that the addition of FF to the matrix improves the flexural modulus over that of a pure geopolymer matrix. Flexural modulus is the measure of resistance to deformation of the composite in bending. It was observed that none of the reinforced specimens were completely broken at peak load. This could be attributed to crack bridging of the long continuous flax fibres under load, which makes the flexural modulus higher than that of pure geopolymer. Long fibres are able to withstand a higher load and are capable of supporting multiple cracks throughout the loading process, consequently preventing brittle failure of the geopolymer.

\section{3 Compressive strength}

The results presented in Fig. 6 show that the compressive strength of the composites containing FF

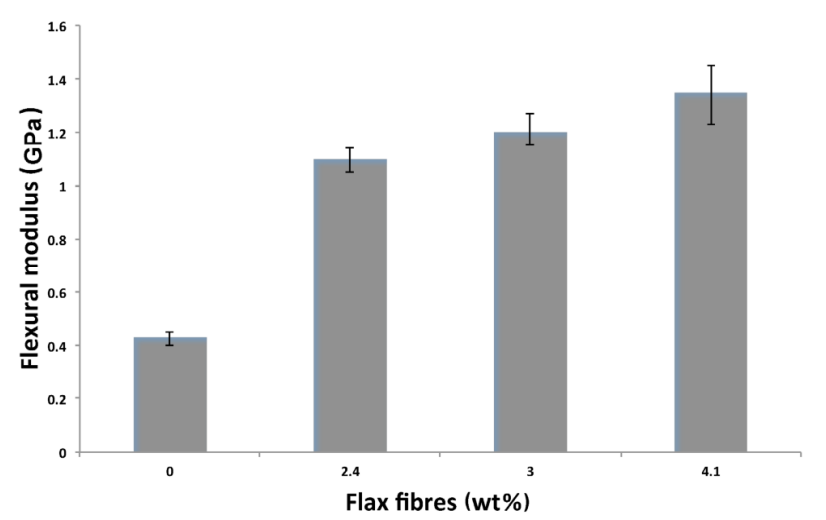

Fig. 5 Flexural modulus of geopolymer composites as a function of fabric content.

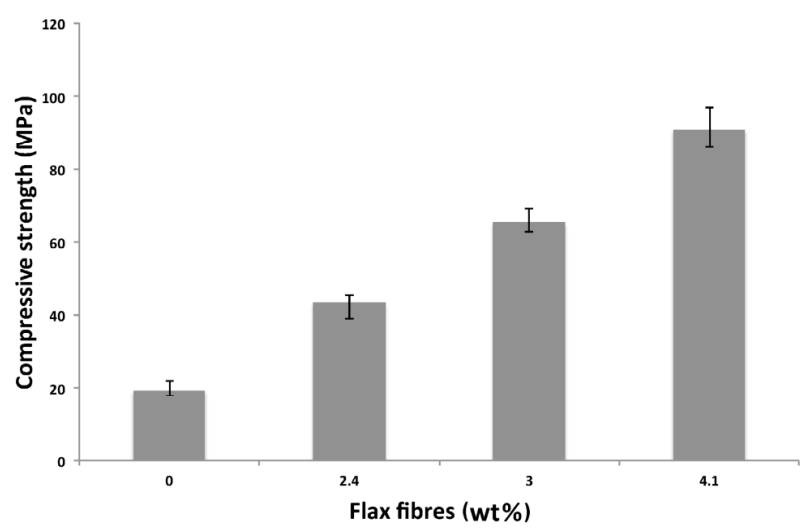

Fig. 6 Compressive strength of geopolymer composites as a function of fabric content.

increases with increase in fibre contents. The increase in compressive strength with fibre loading may be due to the ability of the flax fibres to absorb stress transferred from the matrix. The compressive strength of the neat geopolymer paste increases from 19.4 to $91 \mathrm{MPa}$ after the addition of $4.1 \mathrm{wt} \%$ flax fibres. This significant enhancement of compressive strength is due to the fact that the interface between the fabric and the matrix is not exposed to any shear loading, which in turn reduces the possibility of fabric detachments or delamination from the matrix at high loads. Similar remarkable improvements in compressive strength have also been reported by Alomayri et al. [38] in the case of cotton fibre reinforced geopolymer composites. They concluded that the increase is due to the ability of horizontally laid cotton fabric to directly absorb and distribute a load uniformly throughout the cross-section.

\section{4 Hardness}

Hardness measurement enables the ability of a material to resist plastic deformation under indentation to be determined. The hardness values of FF reinforced geopolymer composites are shown in Fig. 7. The results show that the hardness of composites increases with the addition of high number of flax fabrics to the geopolymer composite. This enhancement in hardness is due to the uniform distribution of the load on the flax fibres, which reduces the penetration of the test ball at the surface of the composite. A similar increase has been reported by other researchers studying natural fibre reinforced geopolymer composites: for instance, Alomayri et al. [25] reported that with increasing cotton fibre content, the hardness value of cotton fibre reinforced geopolymer composites increases. 


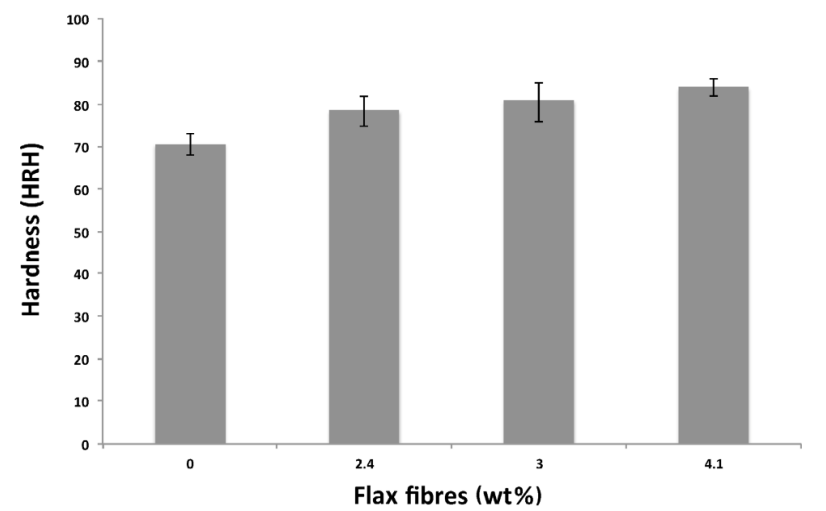

Fig. 7 Hardness of geopolymer composites as a function of fabric content.

\section{5 Fracture toughness}

Generally, fibres' ability to resist crack deflection, debonding, and to bridge cracks, slows down crack propagation in fibre reinforced composites and increases the fracture energy [39-42]. Figure 8 shows the influence of FF content on the fracture toughness of geopolymer composites. It can be seen that the composites containing FF show significantly higher fracture toughness than pure geopolymer matrix, and the higher the FF content, the higher is the fracture toughness. The greatest improvement in fracture toughness was obtained from about $0.4 \mathrm{MPa} \cdot \mathrm{m}^{1 / 2}$ in the pure matrix to about $1.8 \mathrm{MPa} \cdot \mathrm{m}^{1 / 2}$ with $4.1 \mathrm{wt} \%$ FF reinforcement. This extraordinary enhancement is due to the unique ability of flax fibre to resist fracture resulted in increased energy dissipation from crack-deflection at the fibre-matrix interface, fibre-debonding, fibre-bridging, fibre pull-out and fracture, clearly shown in the SEM images (see Figs. 9(a)-9(f)). It can be seen in these images that small pieces of geopolymer paste attached to the fibre surface of the composites: such retention of the matrix on the fibre surfaces shows good adhesion between fibres and

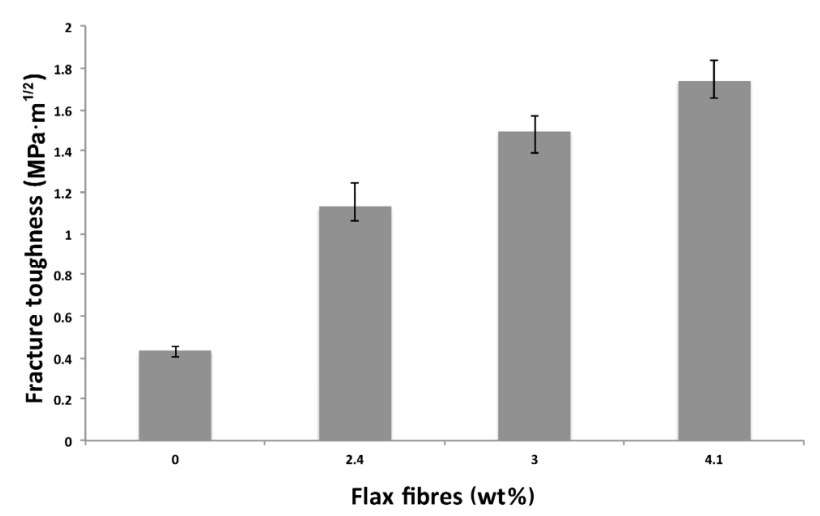

Fig. 8 Fracture toughness of geopolymer composites as a function of fabric content. matrix. It was observed that the composites with fibres do not completely break into pieces, as the close spacing of woven FF leads to crack-bridging by fibres and enhancing the resistance to their propagation. The effect of fibre content on the fracture surface can be seen by observing the difference between the matrix region and the fibre region. In Figs. 10(a) and 10(b), composites filled with lower fibre contents (2.4 and $3.0 \mathrm{wt} \%$ ) show an increase in matrix-rich regions, which means there are insufficient fibres to transfer the load from the matrix. Due to this reason, the geopolymer composites with low fibre content exhibit low fracture toughness and mechanical properties. However, Fig. 10(c) illustrates the fracture surfaces of the geopolymer composites with higher fibre content, which means higher fibre-rich regions of composites with $4.1 \mathrm{wt} \%$ of FF. An increase in fibre-rich regions leads to greater stress-transfer from the matrix to the FF thereby resulting in improvement of fracture toughness.

\section{6 Thermal stability}

The thermal stability of samples was determined using thermogravimetric analysis (TGA). In this test, thermal stability was studied in terms of the weight loss percentage as a function of temperature in argon atmosphere. The thermograms (TGA) of FF, neat geopolymer, and FF reinforced geopolymer composite are shown in Fig. 11.

The thermogram of flax fibres shows degradation in three steps. The first transition occurs from 25 to approximately $240{ }^{\circ} \mathrm{C}$, with the release of free water evaporation. Then, the largest weight loss occurred between 240 and $365{ }^{\circ} \mathrm{C}$ is due to the decomposition of cellulose. This result is in agreement with Alzeer and MacKenzie [27], where the highest weight loss of short flax fibres under flowing air is in the range of 240-340 ${ }^{\circ} \mathrm{C}$. The final stage occurs above $365{ }^{\circ} \mathrm{C}$, when the fibres start to decompose but display a lower rate of weight loss, and all volatile substances are dispelled.

The pure geopolymer shows weight loss occurring from 25 to $300{ }^{\circ} \mathrm{C}$, caused by the evaporation of physically adsorbed water. Above $300{ }^{\circ} \mathrm{C}$, weight loss is attributed to the dehydroxylation of the chemically bound water. The FF reinforced geopolymer composite shows a weight loss of $10.5 \%$ up to about $260{ }^{\circ} \mathrm{C}$, which is due to the evaporation of physically absorbed water. Above $260{ }^{\circ} \mathrm{C}$, the composite shows further weight loss because of the degradation of the fibre content in the sample. The porosity of geopolymer matrix allows the 

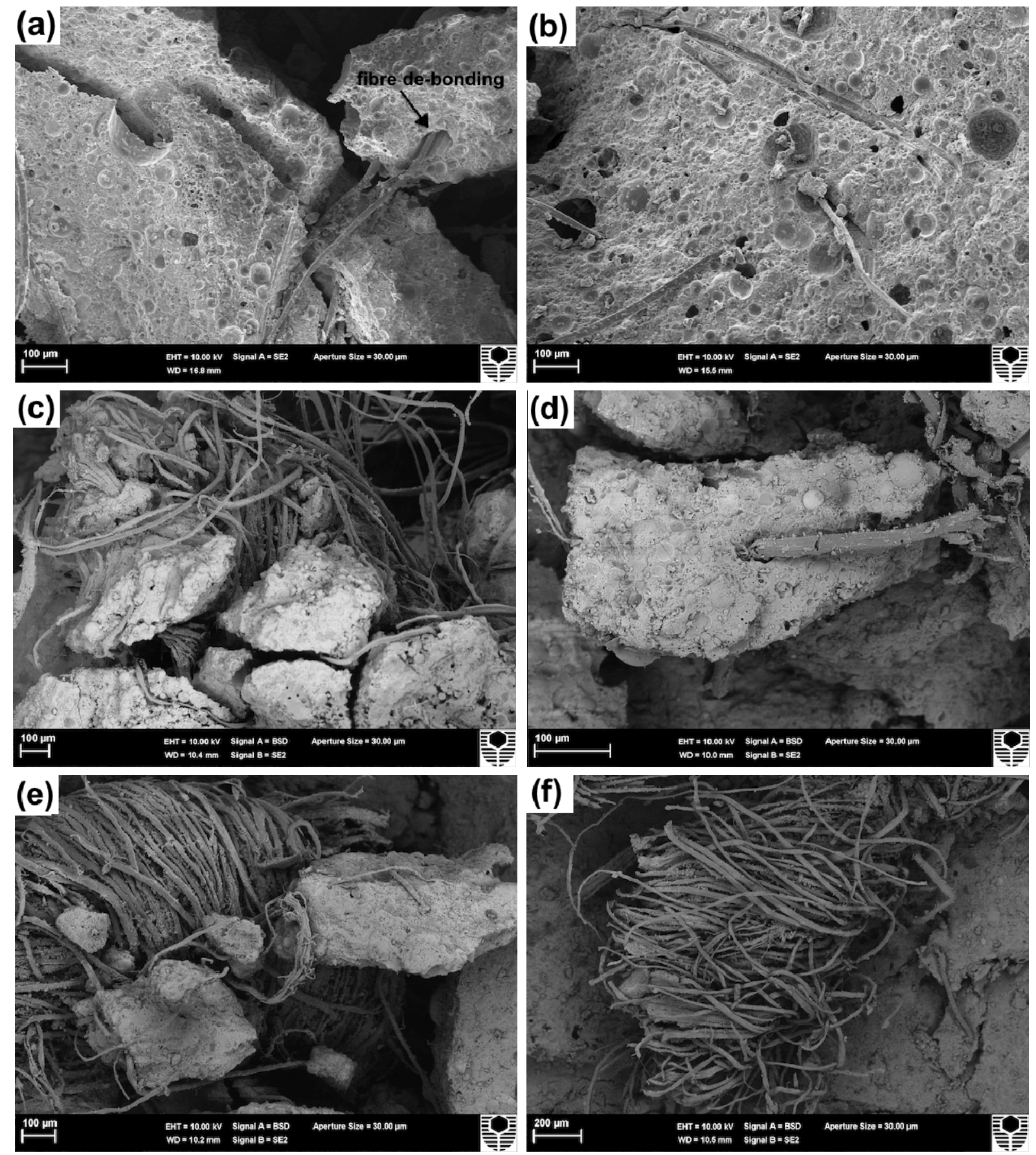

Fig. 9 SEM images of the fracture surface for geopolymer composites reinforced with flax fibres show (a) fibre debonding, (b) fibre imprint and pull-out, (c) fibre bridging cracks ((d) and (e) show the adhesion between fibre and matrix), and (f) fibre fracture.

oxygen to enter and cause degradation of the flax fibres at high temperatures. The composite shows a total weight loss of $\sim 15 \%$ at $300{ }^{\circ} \mathrm{C}$ which indicates further degradation of fibres inside the composite. At this temperature a substantial amount of fibre degradation has occurred. Therefore, it could be concluded that this composite system is only suitable for service below $250{ }^{\circ} \mathrm{C}$. It is worth mentioning here that the TGA micro-sample is not necessarily representative of the whole composite sample because the distribution of flax fibres is not uniform within the geopolymer matrix. Therefore, the fibre content of the TGA micro-sample will be highly dependent on the position it is taken from the composite sample. However, TGA test can provide a good estimation of the thermal stability of a composite when compared to the thermal stability of its components. 


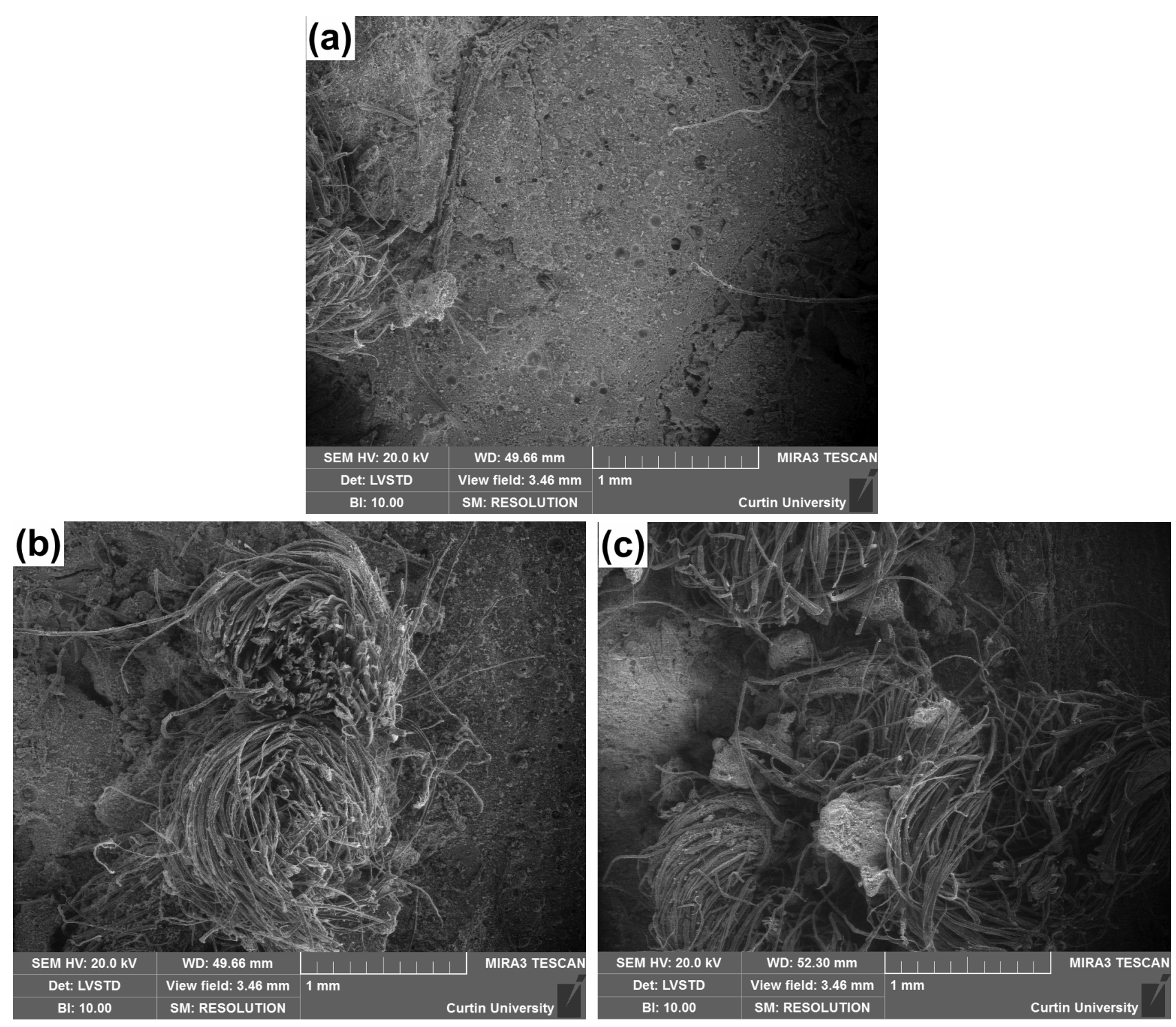

Fig. 10 Low magnification SEM images of the fracture surface for geopolymer composites reinforced with (a) 2.4, (b) 3.0, and (c) $4.1 \mathrm{wt} \%$ of flax fibres.

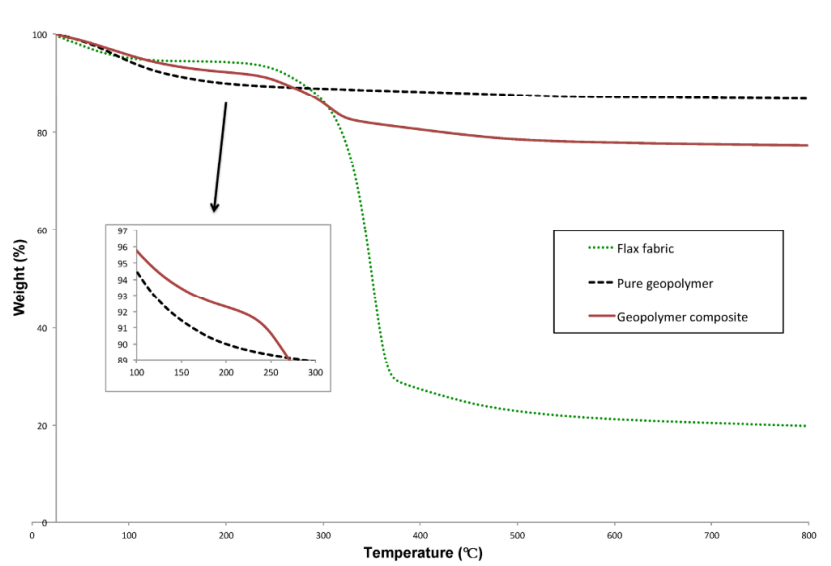

Fig. 11 TGA curves of the flax reinforced geopolymer composite, the matrix, and the flax fibres.

\section{Conclusions}

This paper presents the mechanical and thermal properties and microstructural characterisation of FF reinforced geopolymer composites. It shows that the presence of FF in geopolymer composites remarkably increases flexural and compressive strength, hardness, and fracture toughness compared to neat geopolymer. These significant enhancements are due to the unique properties of flax fibres in resisting greater bending and fracture forces than the more brittle geopolymer. SEM micrographs show a number of toughening mechanisms that include crack bridging, fibre pull-out, and fibre fracture; these are the major factors contributing to the 
enhanced mechanical properties of $\mathrm{FF}$ reinforced geopolymer composites. Thermogravimetric analysis of the samples indicates that the FF reinforced geopolymer exhibits higher net weight loss than pure geopolymer due to the degradation of flax fibres.

\section{Acknowledgements}

The authors would like to thank Ms. E. Miller from the Department of Applied Physics at Curtin University for her assistance with the SEM. The authors would also thank Mr. Les Vickers of Applied Physics and Mr. Andrew Chan of Chemical Engineering at Curtin University for the help with the TGA.

Open Access: This article is distributed under the terms of the Creative Commons Attribution License which permits any use, distribution, and reproduction in any medium, provided the original author(s) and the source are credited.

\section{References}

[1] Barbosa VFF, MacKenzie KJD, Thaumaturgo C. Synthesis and characterization of materials based on inorganic polymers of alumina and silica: Sodium polysialate polymers. Int J Inorg Mater 2000, 2: 309-317.

[2] Davidovits J. Geopolymers: Inorganic polymeric new materials. J Therm Anal 1991, 37: 1633-1656.

[3] Duxson P, Fernández-Jiménez A, Provis JL, et al. Geopolymer technology: The current state of the art. J Mater Sci 2007, 42: 2917-2933.

[4] Temuujin J, van Riessen A, MacKenzie KJD. Preparation and characterization of fly ash based geopolymer mortars. Constr Build Mater 2010, 24: 1906-1910.

[5] Pernica D, Reis PNB, Ferreira JAM, et al. Effect of test conditions on the bending strength of a geopolymerreinforced composite. J Mater Sci 2010, 45: 744-749.

[6] Kriven WM, Bell JL, Gordon M. Microstructure and microchemistry of fully-reacted geopolymers and geopolymer matrix composites. In Advances in Ceramic Matrix Composites IX, Volume 153. Bansal NP, Singh JP, Kriven WM, et al. Eds. Hoboken, NJ, USA: John Wiley \& Sons, Inc., 2006, DOI: 10.1002/9781118406892.ch15.

[7] Lin T, Jia D, He P, et al. Effects of fiber length on mechanical properties and fracture behavior of short carbon fiber reinforced geopolymer matrix composites. Mat Sci Eng A 2008, 497: 181-185.

[8] Hung TD, Pernica D, Kroisová D, et al. Composites base on geopolymer matrices: Preliminary fabrication, mechanical properties and future application. Adv Mat Res 2008, 55-57: 477-480.

[9] Rill E, Lowry DR, Kriven WM. Properties of basalt fiber reinforced geopolymer composites. In Strategic Materials and Computational Design: Ceramic Engineering and Science Proceedings, Volume 31. Kriven WM, Zhou Y, Radovic M, et al. Eds. Hoboken, NJ, USA: John Wiley \& Sons, Inc., 2010, DOI: 10.1002/9780470944103.ch6.

[10] Silva FJ, Thaumaturgo C. Fibre reinforcement and fracture response in geopolymeric mortars. Fatigue Fract Eng $M$ 2003, 26: 167-172.

[11] Vijai K, Kumuthaa R, Vishnuram BG. Properties of glass fibre reinforced geopolymer concrete composites. Asian Journal of Civil Engineering (Building and Housing) 2012, 13: $511-520$.

[12] Zhao Q, Nair B, Rahimian T, et al. Novel geopolymer based composites with enhanced ductility. J Mater Sci 2007, 42: 3131-3137.

[13] Dweib MA, Hu B, O'Donnell A, et al. All natural composite sandwich beams for structural applications. Compos Struct 2004, 63: 147-157.

[14] Tanobe VOA, Sydenstricker THD, Munaro M, et al. A comprehensive characterization of chemically treated Brazilian sponge-gourds (luffa cylindrical). Polym Test 2005, 24: 474-482.

[15] Chandramohan D, Marimuthu K. A review on natural fibers. IJRRAS 2011, 8: 194-206.

[16] Beckwith SW. Natural fibers: Nature providing technology for composites. SAMPE J 2008, 44: 64-65.

[17] Low IM, Schmidt P, Lane J. Synthesis and properties of cellulose-fibre/epoxy laminates. J Mater Sci Lett 1995, 14: 170-172.

[18] Low IM, Somers J, Pang WK. Synthesis and properties of recycled paper-nano-clay-reinforced epoxy eco-composites. Key Eng Mat 2007, 334-335: 609-612.

[19] Zadorecki P, Michell AJ. Future prospects for wood cellulose as reinforcement in organic polymer composites. Polym Composite 1989, 10: 69-77.

[20] McGrath M, Vilaiphand W, Vaihola S, et al. Synthesis and properties of clay- $\mathrm{ZrO}_{2}$-cellulose fibre-reinforced polymeric nano-hybrids. In Proceedings of Structural Integrity and Fracture International Conference, Brisbane, 2004: 265-270.

[21] Panaitescu DM, Vuluga DM, Paven H, et al. Properties of polymer composites with cellulose microfibrils. Mol Cryst Liq Cryst 2008, 484: 86-98.

[22] Low IM, Somers J, Kho HS, et al. Fabrication and properties of recycled cellulose fibre-reinforced epoxy composites. Compos Interface 2009, 16: 659-669.

[23] Rahman MM, Rashid MH, Hossain MA, et al. Performance evaluation of bamboo reinforced concrete beam. International Journal of Engineering \& Technology 2011, 11: $113-118$.

[24] Lin X, Silsbee MR, Roy DM, et al. Approaches to improve the properties of wood fiber reinforced cementitious composites. Cement Concrete Res 1994, 24: 1558-1566.

[25] Alomayri T, Shaikh FUA, Low IM. Effect of fabric orientation on mechanical properties of cotton fabric reinforced geopolymer composites. Mater Design 2014, 57 : 360-365.

[26] Alzeer M, MacKenzie KJD. Synthesis and mechanical 
properties of new fibre-reinforced composites of inorganic polymers with natural wool fibres. J Mater Sci 2012, 47: 6958-6965.

[27] Alzeer M, MacKenzie K. Synthesis and mechanical properties of novel composites of inorganic polymers (geopolymers) with unidirectional natural flax fibres (phormium tenax). Appl Clay Sci 2013, 75-76: 148-152.

[28] ASTM International. ASTM D790, Standard test methods for flexural properties of unreinforced and reinforced plastics and electrical insulating materials. ASTM International, West Conshohocken, PA, USA, 2015.

[29] Low IM, McGrath M, Lawrence D, et al. Mechanical and fracture properties of cellulose-fibre-reinforced epoxy laminates. Composites Part A 2007, 38: 963-974.

[30] ASTM International. ASTM C109/C109-12, Standard test method for compressive strength of hydraulic cement mortars (using 2-in. or [50-mm] cube specimens). ASTM International, West Conshohocken, PA, USA, 2013.

[31] Phair JW, Van Deventer JSJ. Effect of the silicate activator $\mathrm{pH}$ on the microstructural characteristics of waste-based geopolymers. Int J Miner Process 2002, 66: 121-143.

[32] Karbowiak T, Ferret E, Debeaufort F, et al. Investigation of water transfer across thin layer biopolymer films by infrared spectroscopy. J Membrane Sci 2011, 370: 82-90.

[33] Lasagabáster A, Abad MJ, Barral L, et al. Application of FTIR spectroscopy to determine transport properties and water-polymer interactions polypropylene(PP)/poly (ethylene-co-vinyl alcohol) (EVOH) blend films: Effect of poly(ethylene-co-vinyl alcohol) content and water activity. Polymer 2009, 50: 2981-2989.
[34] Zaharaki D, Komnitsas K, Perdikatsis V. Use of analytical techniques for identification of inorganic polymer gel composition. J Mater Sci 2010, 45: 2715-2724.

[35] Tserki V, Zafeiropoulos NE, Simon F, et al. A study of the effect of acetylation and propionylation surface treatments on natural fibres. Composites Part A 2005, 36: 1110-1118.

[36] Abanilla MA, Karbhari VM, Li Y. Interlaminar and interlaminar durability characterization of wet layup carbon/epoxy used in external strengthening. Composites Part B 2006, 37: 650-661.

[37] Sim J, Park C, Moon DY. Characteristics of basalt fiber as a strengthening material for concrete structures. Composites Part B 2005, 36: 504-512.

[38] Alomayri T, Shaikh FUA, Low IM. Synthesis and mechanical properties of cotton fabric reinforced geopolymer composites. Composites Part B 2014, 60: 36-42.

[39] Reis JML. Fracture and flexural characterization of natural fiber-reinforced polymer concrete. Constr Build Mater 2006, 20: 673-678.

[40] Silva FA, Mobasher B, Filho RDT. Cracking mechanisms in durable sisal fiber reinforced cement composites. Cement Concrete Comp 2009, 31: 721-730.

[41] Silva FA, Filho RDT, Filho JAM, et al. Physical and mechanical properties of durable sisal fiber-cement composites. Constr Build Mater 2010, 24: 777-785.

[42] Filho RDT, Ghavami K, England GL, et al. Development of vegetable fibre-mortar composites of improved durability. Cement Concrete Comp 2003, 25: 185-196. 